\title{
Uma Metodologia e Estudo de Caso para a Escolha e Adoção de Software Livre no Ensino Superior de Música
}

\author{
Luan Luiz Gonçalves ${ }^{1}$, Flávio Luiz Schiavoni ${ }^{1}$ \\ ${ }^{1}$ Departamento de Computação \\ ALICE - Arts Lab in Interfaces, Computers, and Everything Else \\ Universidade Federal de São João del-rei \\ São João Del Rei - MG - Brasil \\ luanlg.cco@gmail.com, fls@ufsj.edu.br
}

\begin{abstract}
Higher education often makes use of tools that are market-oriented and not created exclusively for teaching, such as in high school. This paper presents a methodology for choosing and adapting FLOSS tools for a University course based on the disciplines offered in it and the activities to be carried out in the context of these disciplines, the categories of tools that allow the execution of these activities and the FLOSS tools that belong to these categories. The article also presents a case study of the use of this methodology in the Department of Music at the Federal University of São João del-Rei. This case study illustrates the use of the proposed methodology and results in a set of tools that are being used for teaching in this Institution.
\end{abstract}

Resumo. O Ensino Superior muitas vezes faz uso de ferramentas que são voltadas para o mercado e não criadas exclusivamente para o ensino. Este artigo apresenta uma metodologia para a escolha e adoção de ferramentas FLOSS para o ensino em Universidades que parte das disciplinas oferecidas em um curso, as atividades a serem realizadas no contexto destas disciplinas, as categorias de ferramentas que permitem a execução destas atividades e as ferramentas FLOSS que pertencem a estas categorias. O artigo traz ainda um estudo de caso da utilização desta metodologia no Departamento de Música da Universidade Federal de São João del-Rei. Este estudo de caso ilustra a utilização da metodologia proposta e traz como resultado um conjunto de ferramentas que estão sendo utilizadas para o ensino nesta instituição.

\section{Introdução}

A implantação do software na educação básica e ensino médio depende do uso de software educacional, voltado para o ensino, e que atua seguindo conceitos como Simulação, Jogos, Exercício-e-prática, Tutoriais e Programação [Valente 2008, Valente 1999, Tarouco et al. 2004]. A escolha de ferramentas para educação passa sempre por diversas discussões que levam em consideração desde o projeto pedagógico[Freire e Prado 1999] até a capacidade do aluno[Gimenes 2001].

Já no Ensino Superior, esta necessidade de utilizar ferramentas voltadas para o ensino não é algo pontual. Muitas vezes, ferramentas que fazem parte da rotina acadêmica não são ferramentas criadas exclusivamente para o ensino mas ferramentas voltadas para a prática profissional e para o exercício da profissão e que são utilizadas também como 
ferramentas de apoio ao ensino. Em cursos superiores, a tarefa de escolher uma ferramentas de apoio ao ensino envolve questões como os custos destas ferramentas, que não foram criadas para o contexto do ensino, a adequação das mesmas à grade dos cursos e a adoção de ferramentas para preparar o aluno para o mercado de trabalho.

No caso do ensino de música, que é utilizado como estudo de caso no presente artigo, as ferramentas utilizadas no mercado de trabalho costumam ter um alto valor de licença para sua aquisição em Universidades e Centros Universitários e também para profissionais recém formados. Por esta razão, a utilização de software livre poderia ser incentivada pois estas aplicações costumam ter custo zero e podem ser utilizadas pelo aluno recém formado no início de sua vida profissional [Wheeler 2005]. Estas ferramentas, também conhecidas por FLOSS (Free Libre Open Source Software), além de gratuitas, são distribuídas com seu código-fonte, o que permitiria sua alteração e adequação de acordo com a necessidade de seu usuário [Campos 2006].

A utilização de software livre no ensino de música tem gerado algumas discussões [Borges 2007, Queiroz 2014, Schiavoni e Gonçalves 2015] e vão além das questões financeiras já apresentadas pois envolvem também questões políticas e sócio econômicas, como aponta [Koefender et al. 2006].

Apesar de haver iniciativas no intuito de mapear ferramentas livres para o apoio de práticas musicais [Amorim 2014, Pinhati e Siqueira 2012], não há uma metodologia que apoie professores e departamentos na escolha destas ferramentas. Diante deste cenário, este artigo apresenta uma possibilidade metodológica de escolha de ferramentas para o ensino de Música e traz um estudo de caso do levantamento e avaliação de aplicações FLOSS para a área de música, juntamente ao Departamento de Música da Universidade Federal de São João del-Rei.

Este artigo está organizado da seguinte forma: A Seção 2 apresenta a metodologia proposta por este trabalho, a Seção 3 apresenta o estudo de caso desta metodologia e a Seção 4 apresenta a Conclusão e Trabalhos futuros.

\section{Metodologia}

A metodologia proposta possui 5 passos:

\section{Passo 1 - Levantamento das disciplinas}

A metodologia proposta parte do levantamento das disciplinas oferecidas pelo(s) curso(s) do departamento ou curso superior em questão. As disciplinas listadas são organizadas e classificadas como obrigatórias ou optativas e podem ser agrupadas por semestres letivos.

\section{Passo 2 - Levantamento das tarefas e atividades}

Uma vez que as disciplinas são listadas, é feito um levantamento de tarefas e atividades comuns à disciplina e que podem ser realizadas com o apoio de software. Este passo pode utilizar como metodologia uma entrevista aberta para a coleta de dados com perguntas feitas dentro de uma conversação informal [Boni e Quaresma 2005, Minayo e Sanches 1993]. Tais entrevistas podem ser feitas com alunos e professores de todas as disciplinas envolvendo os alunos do curso e alunos egressos.

A partir destas entrevistas, é possível elaborar uma lista de atividades que costumam ser realizadas no contexto do ensino do curso com foco nas tarefas que os alunos 
costumam executar no decorrer do mesmo. Apesar de o objetivo desta pesquisa ser o levantamento de ferramentas, é importante notar que as entrevistas devem focar às tarefas e não os aplicativos para a) evitar relacionar diretamente uma disciplina com uma ferramenta computacional; e b) levantar tarefas comuns que ainda não possuem suporte computacional e que poderiam contar com este suporte.

As entrevistas devem ser transcritas e as atividades podem ser grifadas na transcrição. Normalmente, atividades são verbos como fazer, realizar, criar, e costumam vir acompanhadas da descrição da atividade. Muitas vezes uma mesma atividade pode ser nomeada de maneira diferente por pessoas diferentes. Uma rodada de elucidação pode ser feita com alguns dos participantes para desambiguações e verificação de que todas as tarefas listadas são realmente distintas e eliminar possíveis tautologias.

\section{Passo 3 - De tarefas para categorias de ferramentas}

Uma vez que temos um levantamento de tarefas e atividades que podem / costumam / devem ser realizadas com suporte computacional, é possível criar uma lista de sugestões de tipos de ferramentas que permitem executar estas tarefas. É possível notar que uma mesma ferramenta pode atender mais de uma atividade, sendo útil em várias disciplinas.

Também é possível que uma mesma atividade ou grupo de atividades seja atendido por um mais de uma ferramenta. Por esta razão, listamos os tipos de ferramentas por categoria, sem associar uma ferramenta diretamente ao tipo de atividade ou disciplina. Os tipos de ferramentas devem ser genéricos e atrelados a sua funcionalidade como Editor de Texto ou Navegador de Internet.

Esperamos, com isto, não tomar a decisão de qual ferramenta utilizar mas permitir uma exploração de grupos de ferramentas que poderiam servir para realizar determinadas atividades.

\section{Passo 4 - Categorias de ferramentas e FLOSS}

Verificado os tipos de software, o próximo passo é agrupar as atividades e ferramentas, verificando quais possibilidades existem entre ferramentas FLOSS que atendem estas atividades e consequentemente pertencem a um grupo. Possivelmente algumas ferramentas podem ter sido sugeridas por alunos e / ou professores durante a aplicação da entrevista.

Tais ferramentas podem servir de base para começar uma investigação de possíveis soluções, já que é esperado que uma pessoa da área terá muito mais contato e conhecimento sobre ferramentas existentes em seu campo de atuação do que o pesquisador que está desenvolvendo este trabalho. Para auxiliar nesta pesquisa, vale a pena perguntar aos entrevistados se os mesmos conhecem os termos em inglês para auxiliar nesta pesquisa.

\section{Passo 5 - Avaliação das ferramentas}

Após termos uma lista de sugestões de ferramentas é possível utilizar uma metodologia de análise para a escolha e adoção de ferramentas no curso utilizando para isto critérios locais como Sistema Operacional, disponibilidade de documentação e tradução. Neste ponto, é possível utilizar diversos frameworks e metodologias de avaliação existentes na literatura vigente para avaliação de ferramentas de ensino. 


\section{Estudo de caso}

A metodologia proposta foi aplicada para a escolha de ferramentas pelo Departamento / Curso de Música da Universidade Federal de São João del-Rei - UFSJ. Este departamento conta com um laboratório de informática com várias máquinas e equipamentos para práticas musicais sem contudo possuir software específicos para as práticas no mesmo. A instituição tentou adquirir software para as práticas de seus alunos neste laboratório mas teve muita dificuldade de especificar suas necessidades devido a uma série de particularidades das leis de licitação.

Para entender o cenário desta pesquisa, este departamento conta com 23 professores que atuam nos cursos de licenciatura nas áreas de Violoncelo, Flauta, Percussão, Piano, Canto Lírico, Violão, Clarineta, Saxofone, Flauta, Viola, Regência, Violino, Trombone, Trompete, Canto Popular e Educação Musical. Com uma entrada anual de 40 alunos e um período de término de curso entre 3 e 4 anos, o curso conta com cerca de 150 alunos divididos entre as áreas já listadas.

Uma particularidade deste departamento de música está no fato de que a cidade de São João del Rei abriga orquestras centenária e que, por esta razão, o curso é bastante voltado para as práticas musicais barrocas, executadas por estas orquestras. Por esta razão, a tecnologia não é um dos focos do curso, apesar de não ser ignorada por professores e alunos.

\subsection{Levantamento das disciplinas}

A pesquisa iniciou-se com o levantamento das disciplinas oferecidas pelo Departamento de Música da UFSJ. Este departamento tem duas qualificações, habilitação em Educação Musical e em Instrumento/Canto.

Diferentemente do curso de música em outras universidades, este departamento oferece diversos cursos específicos para seus alunos de habilitação em instrumentos. Tais cursos possuem diversas disciplinas em comum e ao menos uma disciplina de prática de instrumento que é individual. Também há uma separação das disciplinas que são específicas ao curso de música e as disciplinas que são comuns a todos cursos de educação desta mesma Instituição.

Para esta pesquisa, selecionamos algumas disciplinas obrigatórios comuns a todos os cursos do departamento, trazendo ainda a informação entre parênteses de quais semestres / turmas cada disciplina possui. As disciplinas obrigatórias escolhidas para nosso estudo foram: a) Instrumento Musicalizador (I, II, III, IV, V, VI, VII e VIII); b) Canto e Coral (A, B, C e D); c) Percepção Musical (I, II, III, IV, V e VI); d) Harmonia (I e II); e) Análise Musical (I e II); f) Percussão (I e II); g) Fundamentos Regência; h) Criação Musical; i) Arranjos e Transcrições.

\subsection{Levantamento das tarefas e atividades}

O segundo passo foi levantar as tarefas e atividades realizadas no escopo de cada uma destas disciplinas. Foram agendadas entrevistas com todos os professores do departamento e cerca de 10 professores concordaram em participar desta pesquisa e foram entrevistados presencialmente ou por "conversas de corredor". Diversos professores declinaram de participar da pesquisa dizendo não possuir nenhum contato com tecnologia em sala de aula 
e por não se sentirem confortáveis para discutir isto enquanto prática de ensino. Mesmo entre os que foram contactados, muitos alegaram que não teriam condições de contribuir por não estarem familiarizados com tecnologia para o ensino de música.

Devido a dificuldade de encontrar presencialmente com todos os professores dispostos a participarem da pesquisa e para realizar a entrevista aberta, utilizamos também um formulário online contendo as mesmas perguntas realizadas na entrevista. $\mathrm{O}$ formulário teve o mesmo papel da entrevista e, de forma mais prática, facilitou e agilizou o levantamento dos depoimentos dos professores. Ao todo, 3 professores responderam o formulário e contribuíram com nossa pesquisa.

Nossa intenção inicial era também entrevistar e conversas com alunos do curso e com egressos. Porém, esta dificuldade de conseguir a contribuição dos professores acabou por dificultar também o contato com os alunos. O curso conta com aulas pela manhã, tarde e noite e por isto seria mais fácil ter acesso aos alunos em sala de aula, o que acabou não acontecendo em diversas turmas. Ao todo, cerca de 30 alunos foram entrevistados diretamente ou por meio de conversas informais. Também foi utilizado um questionário online para coletar dados dos alunos e cerca de 14 alunos responderam este questionário.

Devido a dificuldade de executar entrevistas, a interação com os professores e alunos também foi feita por meio de outras atividades do pesquisador no Departamento de Música como a atuação como monitor de uma disciplina optativa de Edição de Partituras e Tecnologias Sonoras e a atuação em um projeto de extensão deste mesmo departamento em um curso de Música e Tecnologia.

Este curso de extensão teve duas turmas com a duração de dois semestres. Cada turma com 10 alunos e todos participaram da pesquisa, em especial na parte de avaliação das ferramentas que será apresentada na Seção 3.5 deste documento. As turmas incluíam alunos do ensino médio, sendo a maioria homens. Também permitimos a participação de alguns alunos da UFSJ para preencher as vagas restante, contendo alunos dos cursos de Engenharia Elétrica e Música.

Entre as várias atividades elencadas como parte da prática das disciplinas listadas anteriormente, algumas estavam presente nas respostas de diversos entrevistados como:

1. Ler, escrever e editorar partituras

2. Gravar e editar áudio

3. Tocar acompanhando gravação / sequenciador

4. Treinar reconhecimento de notas e sons

5. Criar sons / manipular áudio em tempo real

6. Fazer arranjos

7. Ouvir a partitura e acompanhar sua execução

Uma vez levantadas estas atividades, entrevistamos novamente os alunos e professores das disciplinas escolhidas para esta pesquisa. Nesta segunda avaliação, em vez de utilizar questionários abertos, utilizamos a lista de atividades e voltamos a mapear em quais disciplinas estas atividades estão presentes, conforme apresentado na Tabela 1.

Esta tabela não lista todas as atividades envolvidas em um curso de música, mas nos dá uma direção na pesquisa em relação ao que podemos esperar ou que os estudantes e professores esperam de apoio tecnológico para estes cursos. 
Tabela 1. Associação entre as atividades e as disciplinas

\begin{tabular}{l|c|c|c|c|c|c|c}
\hline Disciplina & \multicolumn{7}{|c}{ Atividades } \\
\hline & 1 & 2 & 3 & 4 & 5 & 6 & 7 \\
\hline Instrumento Musicalizador & $\mathrm{X}$ & $\mathrm{X}$ & $\mathrm{X}$ & & & & $\mathrm{X}$ \\
Canto e Coral & $\mathrm{X}$ & $\mathrm{X}$ & $\mathrm{X}$ & & & $\mathrm{X}$ & $\mathrm{X}$ \\
Percepção Musical & & & & $\mathrm{X}$ & & & $\mathrm{X}$ \\
Harmonia & $\mathrm{X}$ & & & & & & $\mathrm{X}$ \\
Análise Musical & $\mathrm{X}$ & $\mathrm{X}$ & & & $\mathrm{X}$ & & $\mathrm{X}$ \\
Percussão & $\mathrm{X}$ & & & & & & $\mathrm{X}$ \\
Fundamentos Regência & $\mathrm{X}$ & $\mathrm{X}$ & $\mathrm{X}$ & & & & $\mathrm{X}$ \\
Criação Musical & $\mathrm{X}$ & & & $\mathrm{X}$ & $\mathrm{X}$ & $\mathrm{X}$ & $\mathrm{X}$ \\
Arranjos e Transcrições & $\mathrm{X}$ & & & $\mathrm{X}$ & $\mathrm{X}$ & $\mathrm{X}$ & $\mathrm{X}$ \\
\hline
\end{tabular}

\subsection{De tarefas para categorias de ferramentas}

Uma vez levantadas as tarefas e atividades, foi levantado os tipos de ferramentas que atendem a estas necessidades. O passo seguinte foi agrupar tais necessidades e verificar quais tipos de ferramentas podem atender de maneira ampla as tarefas propostas. Os grupos de ferramentas e a relação com as atividades é apresentado na Tabela 2.

Tabela 2. Associação entre as atividades e as categorias de ferramentas
\begin{tabular}{l|c|c|c|c|c|c|c}
\hline Categoria & \multicolumn{7}{|c|}{ Atividades } \\
\hline Editor de Partitura & X & & X & X & & X & X \\
Sequenciamento & X & & X & & & X & X \\
Acompanhamento & $\mathrm{X}$ & & $\mathrm{X}$ & & & & \\
Editor de áudio & & $\mathrm{X}$ & & & $\mathrm{X}$ & & \\
Tocador de áudio & & & $\mathrm{X}$ & & & $\mathrm{X}$ & $\mathrm{X}$ \\
Analisador de áudio & & & & $\mathrm{X}$ & & & \\
Testes de percepção & & & & $\mathrm{X}$ & & & \\
\hline
\end{tabular}

Podemos notar aqui que uma mesma categoria de ferramenta consegue atender diversas atividades descritas como parte das práticas das disciplinas listadas.

\subsection{Categorias de ferramentas e FLOSS}

Uma vez listadas as categorias de ferramentas que poderiam atender estas atividades, o próximo passo foi encontrar ferramentas FLOSS que permitem realizar tais atividades. Devido à dificuldade de os alunos e professores utilizarem o sistema operacional Linux, foi listado também quais sistemas operacionais permitem a instalação destas ferramentas. As ferramentas encontradas são listadas na Tabela 3 .

Com isto, chegamos a uma lista de ferramentas FLOSS para o apoio ao ensino de música elencando quais atividades em quais disciplinas podem ser atendidas pelas ferramentas aqui apresentadas. 
Tabela 3. Aplicativos associados à categoria

\begin{tabular}{l|l|c}
\hline Categorias & Ferramentas FLOSS & \multicolumn{1}{c}{ Sistema operacional } \\
\hline Editor de Partitura & MuseScore $^{1}$ & Linux, Windows, MacOS \\
\hline Sequenciamento & LMMS $^{2}$ & Linux, Windows, MacOS \\
\hline Acompanhamento & LinuxBand $^{3}$ & Linux \\
\hline \multirow{2}{*}{ Editor de Áudio } & Ardour $^{4}$ & Linux, Windows, MacOS \\
\cline { 2 - 3 } & Audacity $^{5}$ & Linux, Windows, MacOS \\
\hline \multirow{2}{*}{ Tocador de áudio } & Audacious $^{6}$ & Linux, Windows \\
\cline { 2 - 3 } & Brasero $^{7}$ & \multicolumn{1}{c}{ Linux } \\
\cline { 2 - 3 } & VLC Media Player $^{8}$ & Linux, Windows, MacOS \\
\hline Analisador de áudio & Sonic Visualiser $^{9}$ & Linux, Windows, MacOS \\
\hline Testes de Percepção & GNU Solfege & Linux, Windows, MacOS \\
\hline
\end{tabular}

\subsection{Avaliação das ferramentas}

Uma vez apresentado um conjunto de ferramentas, escolhemos um subgrupo das mesmas para realizar uma avaliação preliminar das mesmas. Entre as ferramentas levantadas, foram escolhidas as seguintes ferramentas para esta avaliação:

- MuseScore;

- LMMS;

- Audacity;

- Sonic Visualiser;

- GNU Solfege.

O fator para a escolha destas ferramentas na lista previamente apresentada foi a disponibilidade das mesmas em diversos sistemas operacionais. Além disto, julgamos que tocadores de áudio são bastante simples e não demandariam avaliações.

A avaliação destas ferramentas foi feita in loco em duas situações: na disciplina optativa Edição de Partituras e Tecnologias Sonoras e no curso de extensão de Música e Tecnologia. Com isto, nossa avaliação pôde atingir dois perfis de usuário distintos, alunos do Departamento de Música e membros da comunidade externa que possuem intenção de ser alunos ingressos nestes cursos. Vale notar que estes perfis são heterogêneos no que tange o conhecimento musical e também computacional de aplicações musicais.

\footnotetext{
${ }^{1}$ Disponível em https://musescore.org/pt-br

${ }^{2}$ Disponível em https://lmms.io/

${ }^{3}$ Disponível em http: // linuxband.org/

${ }^{4}$ Disponível em http://ardour.org/

${ }^{5}$ Disponível em http://audacityteam.org/? lang=pt-BR

${ }^{6}$ Disponível em http://audacious-media-player.org/

${ }^{7}$ Disponível em http://wiki.ubuntu-br.org/Brasero

${ }^{8}$ Disponível em www.videolan.org/vlc/

${ }^{9}$ Disponível em http: //www. sonicvisualiser.org/

${ }^{10}$ Disponível em https://www.gnu.org/software/solfege/
} 
Para executar esta avaliação, foi oferecido um mini curso com as ferramentas selecionadas acompanhado de uma série de atividades básicas a serem executadas utilizando cada uma delas. A avaliação das ferramentas por parte dos usuários foi bastante positiva e no geral não houve grandes dificuldades para sua utilização.

A ferramenta MuseScore é comumente comparada com ferramentas proprietárias da mesma categoria (Editor de partitura). A utilização desta ferramenta por usuários experientes foi relatada como muito satisfatória devido a facilidade de configurar as teclas de atalho deste aplicativo de modo que o mesmo possa mimetizar as aplicações proprietárias. Com isto, os usuários mais experientes conseguiram bons resultados com a mesma. Foi notado que os usuários menos experientes possuíam também pouca experiência com escrita de partitura e que, mesmo assim, a possibilidade de ensinar teoria musical junto com a ferramenta auxiliou ultrapassar esta barreira.

O Sequenciador LMMS apresentou-se como uma ferramenta bastante simples de ser usada e bastante poderosa e que possibilita um universo de criação musical. Apesar de vários alunos terem realizado trabalhos satisfatórios, houve um pouco de dificuldade na aceitação dos resultados obtidos pelos próprios alunos devido a necessidade de criatividade para compor uma trilha nova.

A prática com a ferramenta Audacity permitiu aos alunos a criação de um programa de rádio. Não houve grandes dificuldades para a realização disto e a ferramenta se apresentou bastante amigável mesmo a usuários menos experientes.

As práticas com a ferramenta Sonic Visualiser apresentaram dificuldades devido à necessidade de possuir conhecimento em visualização de características musicais como espectrograma e timbres. Tal ferramenta certamente será melhor utilizada se aplicada em uma disciplina que trate também do conhecimento necessário para utilizá-la. Já o GNU Solfege se mostrou bastante simples e intuitivo para o treinamento auditivo musical.

\subsubsection{Avaliação geral}

A avaliação das ferramentas apontou que algumas características são importantes para a aceitação das mesmas em um ambiente de ensino. Entre estas características estão:

- Tradução em português;

- Disponibilidade em vários sistemas operacionais;

- Existência de documentação, exemplos e tutoriais em português.

Uma dificuldade comumente encontrada para uma boa aceitação da ferramenta no ambiente de ensino está relacionada ao conhecimento técnico necessário para entender os fundamentos necessários para operar as ferramentas. Notamos, por exemplo, que um conhecimento técnico de áudio simplifica muito o entendimento de plugins de áudio na ferramenta Audacity já que os usuários tiveram dificuldades para entender o que é um determinado efeito em áudio e que esta dificuldade poderia ser confundida com a dificuldade de utilizar o plugin em si. Esta dificuldade seria facilmente transposta se o contexto da pesquisa fosse a utilização da ferramenta em uma disciplina cujas atividades estão relacionadas a este conhecimento. Por fim, notamos que ainda há um receio em utilizar software livre por parte dos alunos devido a uma dificuldade de entender que um software pode ter qualidade e ainda assim ser livre. 


\section{Conclusão}

Este trabalho apresentou uma metodologia para escolha e adoção de ferramentas FLOSS para o ensino em cursos universitários. A metodologia parte do levantamento das disciplinas obrigatórias do curso e das atividades associadas a cada disciplina. O levantamento de atividades leva a escolha de categorias de ferramentas que atendem estas atividades e as categorias levam a um grupo de ferramentas FLOSS que fazem parte desta categoria. Uma vez que chegamos a um grupo de ferramentas, a metodologia proposta prevê uma avaliação destas ferramentas antes da adoção das mesmas no ambiente de ensino utilizando para isto critérios que são importantes localmente como disponibilidade em diversos sistemas operacionais ou tradução para o português. Esta metodologia foi utilizada como um estudo de caso no Departamento de Música da UFSJ e ilustra a utilização da metodologia proposta para o contexto do ensino de música.

Como resultado, apresentamos uma lista de ferramentas para atender as necessidades de programas de computador do Departamento de Música desta instituição junto com a instalação e treinamento das ferramentas apresentadas no laboratório de ensino do Departamento de Música. Tal laboratório possuía, no início desta pesquisa, poucos aplicativos instalados devido a questões de licença e esta pesquisa trouxe para os alunos as ferramentas aqui listadas juntamente com a possibilidade de utilizar o computador no contexto de várias disciplinas do curso. Apesar de nem todos os alunos ter passado por um treinamento nas ferramentas instaladas, a disponibilização de material de ensino em português e a existência de colegas com conhecimento na utilização destas ferramentas auxiliou na aceitação das mesmas por alunos e professores.

Acreditamos que esta metodologia auxiliou na escolha das ferramentas para estes cursos e permitiu que alunos e professores entendessem claramente quais atividades de quais disciplinas poderiam ser atendidas com uma mesma ferramenta, por exemplo. Além disto, a metodologia proposta permite que os alunos e professores busquem por ferramentas alternativas para determinada atividade no caso de não se sentirem satisfeitos com a sugestão encontrada no escopo desta pesquisa.

Esta metodologia pode ser facilmente utilizada para a escolha de ferramentas computacionais de outros cursos e permitiria uma visão bastante clara da necessidade de aplicativos no contexto de ensino em um departamento ou instituição.

No entanto, ainda há alguns problemas para resolver que nos eram desconhecidos mas que identificamos na realização desta pesquisa. Quanto iniciamos esta pesquisa, não esperávamos encontrar resistência por parte de professores e alunos e isto nos surpreendeu pois acreditamos que o emprego de tecnologia em cursos de artes seria hoje uma necessidade cada vez mais presente, tanto no curso superior quanto nos ensinos básicos e cursos livres. Esta resistência, identificada no âmbito desta pesquisa nos faz refletir o quanto ainda é necessário um convencimento de que o emprego da tecnologia na educação é um problema para além da discussão tecnológica e que tal problema precisa passar por uma discussão didática e pedagógica.

Vale ressaltar que, apesar de muitos professores e alunos optarem por não participar da pesquisa alegando não poder contribuir devido a não estarem familiarizados com tecnologia, todos assumiram que esta pesquisa era de suma importância para o Curso e que os egressos deveriam possuir domínio das tecnologias aqui discutidas. Assim, acredi- 
tamos que esta pesquisa trouxe o resultado aqui e também permitiu trazer à tona a discussão de emprego de ferramentas tecnológicas em um curso acadêmico onde a tecnologia se faz presente e pode ser fundamental para o exercício da profissão do egresso.

\subsection{Agradecimentos}

Os autores gostariam de agradecer ao CNPq (151975/2019-1), a FAPEMIG (APQ-0214818), a Universidade Federal de São João del-Rei e aos membros do laboratório ALICE Arts Lab in Interfaces, Computers, Education and Else - pelo apoio a esta pesquisa.

\section{Referências}

Amorim, J. N. d. (2014). O ensino do contrabaixo elétrico e as novas ferramentas tecnológicas: um estudo de caso na escola de música de brasília.

Boni, V. and Quaresma, S. J. (2005). Aprendendo a entrevistar: como fazer entrevistas em ciências sociais. Em Tese, 2(1):68-80.

Borges, G. A. (2007). Musix gnu linux na sala de aula. possibilidades de uso de softwares livres na educação musical.

Campos, A. (2006). O que é software livre. BR-Linux. Florianópolis, março de.

Freire, F. M. P. and Prado, M. (1999). Projeto pedagógico: Pano de fundo para escolha de um software educacional. O computador na sociedade do conhecimento. Campinas, SP: UNICAMP-NIED, pages 111-129.

Gimenes, M. C. (2001). A utilização do computador na educação. Educere-Revista da Educação da UNIPAR, 1(2).

Koefender, J., Nakahara, K. C., Savi, R., and Dantas, W. S. (2006). Software livre na educação: A experiência do projeto classificação de software livre educativo (classe). RENOTE, 4(1).

Minayo, M. d. S. and Sanches, O. (1993). Quantitativo-qualitativo: oposição ou complementaridade. Cadernos de saúde pública, 9(3):239-262.

Pinhati, F. and Siqueira, S. (2012). Utilização de ferramentas colaborativas na aprendizagem musical de alunos leigos. In Anais do Workshop de Informática na Escola, volume 1 .

Queiroz, L. R. (2014). Educação musical e cultura: singularidade e pluralidade cultural no ensino e aprendizagem da música. Revista da ABEM, 12(10).

Schiavoni, F. L. and Gonçalves, L. L. (2015). Utilização de software livre no ensino de música da ufsj. In SBCM 2015, pages 60-67, Campinas - SP - Brazil.

Tarouco, L. M. R., Roland, L. C., Fabre, M.-C. J. M., and Konrath, M. L. P. (2004). Jogos educacionais. RENOTE: revista novas tecnologias na educação [recurso eletrônico]. Porto Alegre, $R S$.

Valente, J. A. (1999). Análise dos diferentes tipos de softwares usados na educação. $O$ computador na sociedade do conhecimento, page 71 .

Valente, J. A. (2008). Diferentes usos do computador na educação. Em Aberto, 12(57).

Wheeler, D. A. (2005). Why open source software/free software (oss/fs, floss, or foss)? look at the numbers! 